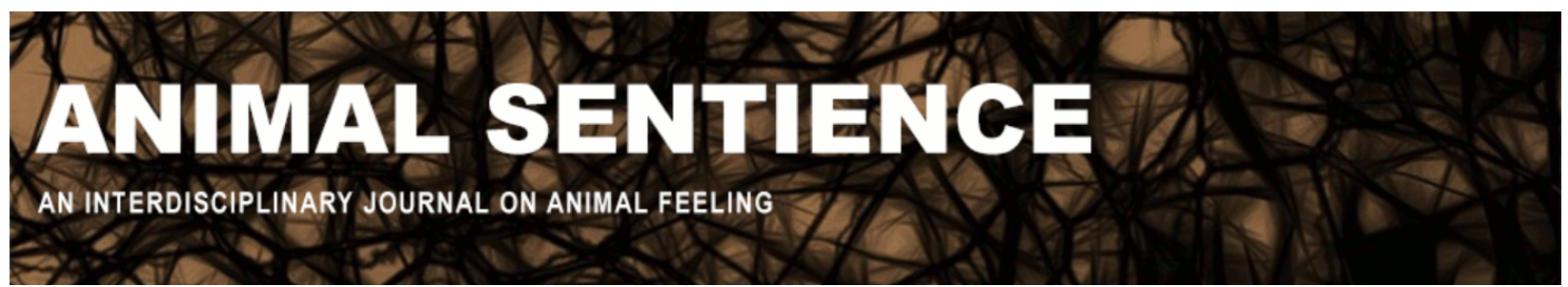

Zentall, Thomas R. (2018) Jealousy, competition, or a contextual cue for reward?. Animal Sentience 22(4)

DOI: $10.51291 / 2377-7478.1331$

Date of submission: 2018-05-21

Date of acceptance: 2018-05-23

(c)

This article has appeared in the journal Animal

Sentience, a peer-reviewed journal on animal

cognition and feeling. It has been made open access,

free for all, by WellBeing International and deposited

in the WBI Studies Repository. For more information,

please contact

wbisr-info@wellbeingintl.org.

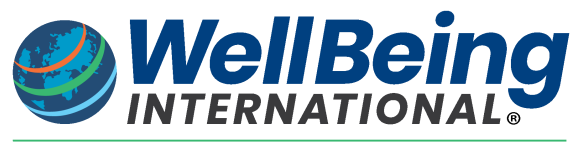

SOLUTIONS FOR PEOPLE, ANIMALS AND ENVIRONMENT 


\title{
Jealousy, competition, or a contextual cue for reward?
}

Commentary on Cook et al. on Dog Jealousy

\author{
Thomas R. Zentall \\ Department of Psychology, University of Kentucky
}

\begin{abstract}
Emotions are difficult to assess, even in humans. The attribution of jealousy in an animal like a dog is especially difficult because performance of a particular behavior in the context of another animal receiving a reward may not be easily distinguishable from intra-species competition or simply a response to a contextual cue for the availability of reward. The authors provide distinguishing evidence in the form of fMRI data to show that in the presence of a "fake" dog being fed, there is bilateral activation in the amygdala, an area associated with anxiety, anger, fear, and even jealousy in humans.
\end{abstract}

Keywords: animal emotion, jealousy, fMRI, competition, cue for obtaining reward

Thomas R. Zentall is the DiSilvestro Endowed
Professor of Arts and Sciences and is a University
Research Professor in the Department of
Psychology at the University of Kentucky,
Lexington, KY. With Edward Wasserman, he has
edited Comparative Cognition: Experimental
Explorations of Animal Intelligence (Oxford
University Press) and The Oxford Handbook of
Comparative Cognition. www.uky.edu/ zentall

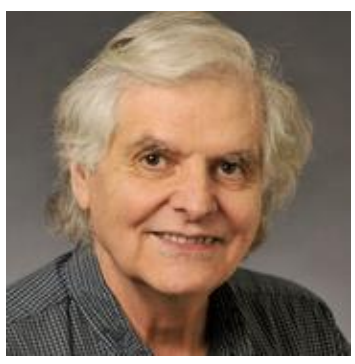

Research on emotions in humans is difficult because the behavior demonstrated is not always consistent with the feeling expressed verbally. Consider crying, an emotion often shown when a missing child has been found. Finding a lost child should be a happy occasion, so one interprets the emotion as happiness rather than sadness. At other times, one depends on the behavior as an indication of an emotion that may be unconscious (e.g., snapping at one's spouse several hours after being criticized by one's boss at work). Thus, one often uses context as a cue to evaluate the underlying emotion because neither the behavior nor the subject's self-described feeling is an accurate measure. Research on animal emotion is considerably more problematic because one cannot even ask the animal about its emotional state, nor would it be appropriate for us as experimenters to interpret the behavioral context in terms of how we would feel under similar circumstances. Instead, typically, we are left with the animal's behavior and the context in which it occurs as the only basis on which to assess the emotion.

Consider the following scenario: Two dogs are lying on the floor. One of them gets up and nuzzles a human (perhaps a request for petting?). Immediately, the other dog gets up and does the same. The human may judge this to be a sign that the second dog is jealous because the first dog is receiving attention. Jealousy implies resentment, involving an unhappy or angry feeling. But what is the second dog actually feeling? Could it be that the sight of the first dog getting attention served as a cue to the second dog that attention is now available? Alternatively, the sight of another dog getting attention may provoke not jealousy but competition in the second dog. Competition does not typically involve anger. Of course, there may be behavioral cues to 
distinguish between attention availability and jealousy. For example, if the second dog growls at the first dog, it would imply some level of hostility, a suggestion of jealousy. However, if the second dog shows little interaction with the first dog, interpreting the second dog's behavior as responding to a cue for a time to get attention or to be competitive might be more parsimonious. What would make this scenario more difficult to interpret would be if, in approaching the human, the second dog nudges the first dog away from the human's petting hand. Should the behavior be interpreted as "I want some of that too", "I need to compete with you to get that attention", or "I resent the fact that you are getting attention and I am not"? How can one get at the underlying emotion of the animal, especially a pet who may have been trained not to behave in an aggressive way?

Cook, Prichard, Spivack, and Berns (2018) suggest that brain imaging (fMRI) may provide a clue. It should be noted that for those of us who do research with animals, the idea of obtaining a brain scan from an awake, unrestrained dog would be a very difficult task, but Berns, Brooks, and Spivack (2012) not only trained dogs to lie still under relatively unfamiliar, noisy conditions but were quite successful in obtaining $f M R I$ scans of dog brains. In their experiment, they compared the brain scans of dogs observing a human feeding a "fake" but realistic-looking appropriately-smelling dog with a control condition (the brain scan of the same dog observing the human putting food into a bucket). Relative to the control condition, in the experimental condition, they reported bilateral amygdala activation, that when found in humans suggests "a range of affective states including anxiety, anger, fear, and even jealousy." Furthermore, this activation was positively correlated with the caregiver's assessment of the temperament of the dog (C-BARQ; Hsu \& Serpell, 2003).

One may distinguish among the human emotions suggested by amygdala activation by appealing to contextual cues or by asking the subject to introspect about the emotion (neither of which may be accurate). Given these caveats, I find the authors' use of the term proto-jealousy to be sufficiently cautious to warrant the claim that something akin to human jealousy or envy was the emotion that was experienced by the dogs in this study. I applaud the authors' carefully designed experiment and their carefully stated conclusion. I suspect that it will challenge other researchers to use these procedures to further explore proto-emotions in animals.

A minor point: I would think that the context in which the dogs' brain was scanned would have been more suggestive of envy than jealousy. Envy may occur when one lacks a desired attribute enjoyed by another, whereas jealousy may occur when something one already possesses is threatened (Parrot \& Smith, 1993).

\section{References}

Berns, G. S., Brooks, A. M., \& Spivak, M. (2012). Functional MRI in awake unrestrained dogs. PLOS ONE, May 11; 7(5), e38027.

Cook, P., Prichard, A., Spivak, M., \& Berns, G. S. (2018). Jealousy in dogs? Evidence from brain imaging. Animal Sentience 22(1).

Hsu, Y., \& Serpell, J. A. (2003). Development and validation of a questionnaire for measuring behavior and temperament traits in pet dogs. Journal of the American Veterinary Medical Association, 223(9), 12931300.

Parrott, W. G., \& Smith, R. H. (1993). Distinguishing the experiences of envy and jealousy. Journal of Personality and Social Psychology, 64, 906-920. 


\section{UQÀM/ISC Cognitive Science Summer School June 26 - July 6 2018, Montreal, Canada}

\section{The Other Minds Problem: Animal Sentience and Cognition}

Overview. Since Descartes, philosophers know there is no way to know for sure what - or whether - others feel (not even if they tell you). Science, however, is not about certainty but about probability and evidence. The 7.5 billion individual members of the human species can tell us what they are feeling. But there are 9 million other species on the planet (20 quintillion individuals), from elephants to jellyfish, with which humans share biological and cognitive ancestry, but not one other species can speak: Which of them can feel - and what do they feel? Their human spokespersons - the comparative psychologists, ethologists, evolutionists, and cognitive neurobiologists who are the world's leading experts in "mind-reading" other species - will provide a sweeping panorama of what it feels like to be an elephant, ape, whale, cow, pig, dog, bat, chicken, fish, lizard, lobster, snail: This growing body of facts about nonhuman sentience has profound implications not only for our understanding of human cognition, but for our treatment of other sentient species.

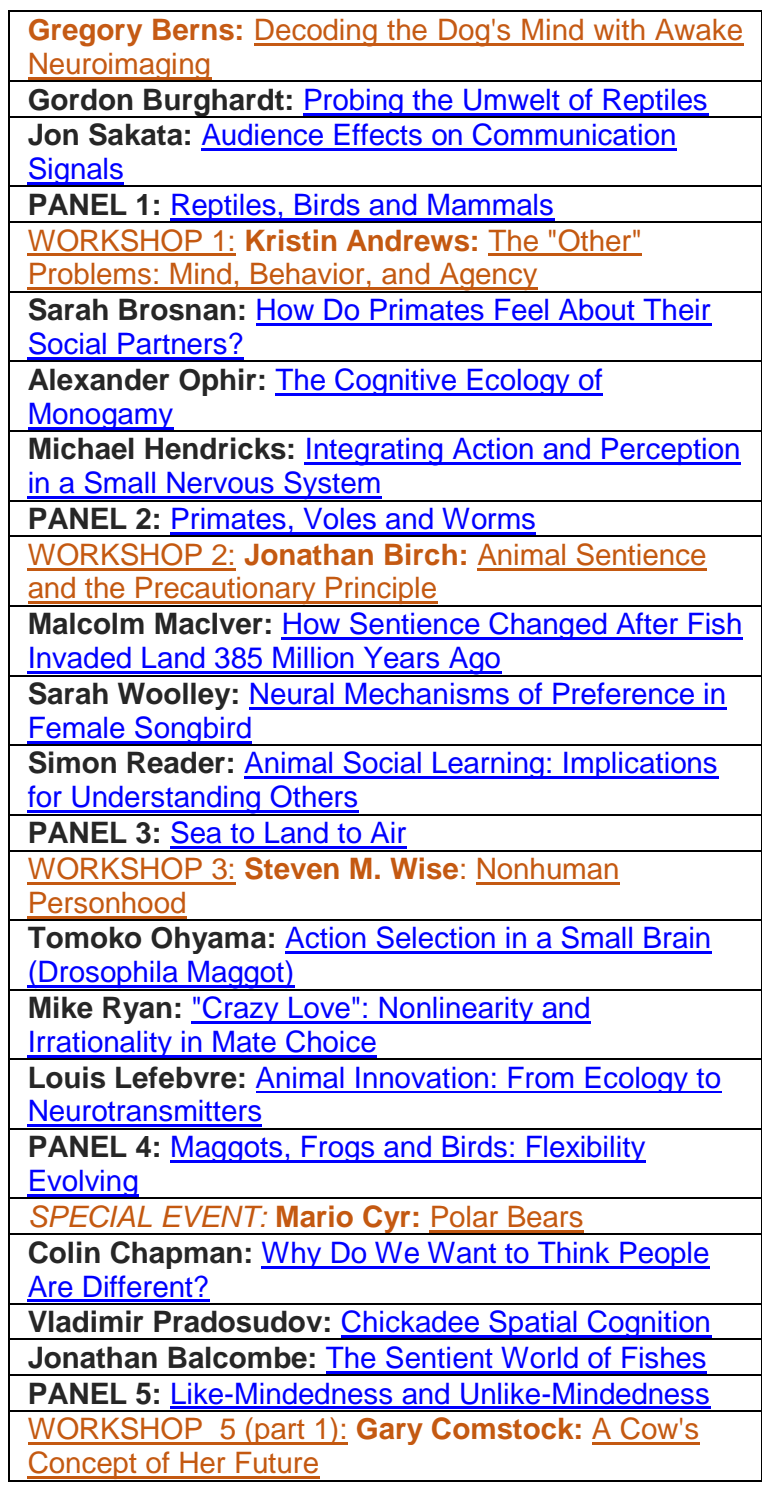

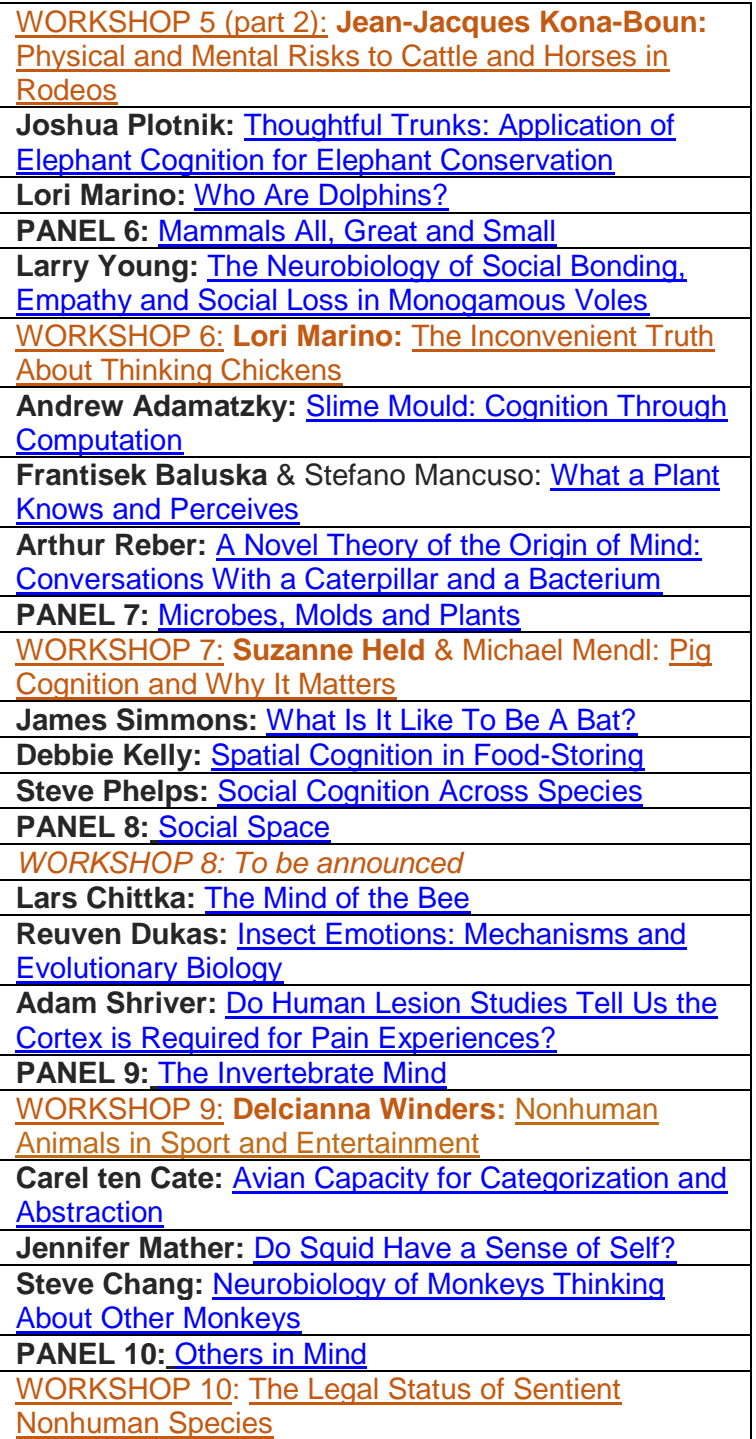

